\title{
Cognitive Distortions in Normal-Weight and Overweight Women: Susceptibility to Thought-Shape Fusion
}

Citation for published version (APA):

Coelho, J. S., Jansen, A., \& Bouvard, M. (2012). Cognitive Distortions in Normal-Weight and Overweight Women: Susceptibility to Thought-Shape Fusion. Cognitive Therapy and Research, 36(4), 417-425. https://doi.org/10.1007/s10608-011-9372-0

Document status and date:

Published: 01/01/2012

DOI:

10.1007/s10608-011-9372-0

Document Version:

Publisher's PDF, also known as Version of record

\section{Document license:}

Taverne

\section{Please check the document version of this publication:}

- A submitted manuscript is the version of the article upon submission and before peer-review. There can be important differences between the submitted version and the official published version of record.

People interested in the research are advised to contact the author for the final version of the publication, or visit the DOI to the publisher's website.

- The final author version and the galley proof are versions of the publication after peer review.

- The final published version features the final layout of the paper including the volume, issue and page numbers.

Link to publication

\footnotetext{
General rights rights.

- You may freely distribute the URL identifying the publication in the public portal. please follow below link for the End User Agreement:

www.umlib.nl/taverne-license

Take down policy

If you believe that this document breaches copyright please contact us at:

repository@maastrichtuniversity.nl

providing details and we will investigate your claim.
}

Copyright and moral rights for the publications made accessible in the public portal are retained by the authors and/or other copyright owners and it is a condition of accessing publications that users recognise and abide by the legal requirements associated with these

- Users may download and print one copy of any publication from the public portal for the purpose of private study or research.

- You may not further distribute the material or use it for any profit-making activity or commercial gain

If the publication is distributed under the terms of Article $25 \mathrm{fa}$ of the Dutch Copyright Act, indicated by the "Taverne" license above, 


\title{
Cognitive Distortions in Normal-Weight and Overweight Women: Susceptibility to Thought-Shape Fusion
}

\author{
Jennifer S. Coelho • Anita Jansen - Martine Bouvard
}

Published online: 24 May 2011

(C) Springer Science+Business Media, LLC 2011

\begin{abstract}
Cognitive distortions may be implicated in difficulties with normalized eating. One specific distortion relevant to eating pathology is "thought-shape fusion" (TSF), in which just imagining eating high-caloric food leads individuals to feel fatter, and to perceive weight gain and moral wrong-doing. The current study investigated whether there are differential responses to TSF inductions in normal-weight versus overweight females. A total of 60 females participated, who were classified as either normalweight $(n=32)$ or overweight $(n=28)$. Participants were randomly assigned to either a TSF or a neutral induction condition, and their responses on TSF questionnaires were assessed. The results indicated that normal-weight individuals reported higher TSF levels after a TSF induction than a control induction, whereas there were no significant differences across conditions for overweight individuals. This suggests that normal-weight females were more susceptible to the TSF induction than were overweight females. The results are discussed in terms of possible differences between normal-weight and overweight females in self-regulation after food-cue exposure.
\end{abstract}

The author Jennifer S. Coelho moved to the University of Savoie during the course of this research.

J. S. Coelho · A. Jansen

Department of Clinical Psychological Science, Faculty

of Psychology and Neuroscience, Maastricht University,

Maastricht, The Netherlands

J. S. Coelho $(\bowtie) \cdot$ M. Bouvard

Interuniversity Laboratory of Psychology, Université de Savoie, BP 1104, 73011 Chambéry cedex, Jacob-Bellecombette, France e-mail: jennifer.coelho@univ-savoie.fr
Keywords Cognitive distortions - Thought-shape fusion . Overweight $\cdot$ Food cue

\section{Introduction}

Substantial long-term weight loss is notoriously difficult. Strategies to aid in weight-loss are presented as relatively simple, such as the "energy balance" equation promoted by the National Institutes of Health which endorses that input of calories through food intake should be less than caloric expenditure (National Institutes of Health 2009). However, it appears that only around $20 \%$ of overweight individuals achieve and maintain long-term weight-loss (Wing and Phelan 2005). Thus, while a substantial minority of individuals who attempt to lose weight are successful, there remain large numbers of individuals who chronically struggle with their weight and fail to meet their weight-loss goals. Meanwhile, the prevalence of overweight and obesity is increasing around the world (e.g., the United States, Japan, Brazil, and England) to the point that it is being labeled as an epidemic that has serious public health implications (e.g., James 2004). Therefore, there is rising interest in factors which can help promote weight loss and weight maintenance.

Part of the difficulty in maintaining a weight within the 'normal' range (i.e., a body mass index (BMI) between 18.5 and 24.9) stems from widespread environmental factors which promote overeating and physical inactivity (e.g., Hill and Peters 1998), including portion sizes, availability of high-caloric foods, and sedentary work and leisure activities. Brownell (2002) has put forth that the toxic food environment is the cause of the current obesity environment. This toxic food environment includes constant exposure to food-related cues. Exposure to food cues 
appears to increase food-related thoughts in weight-concerned individuals (i.e., individuals high in dietary restraint), and also leads to increased intake (Fedoroff et al. 1997). Overweight individuals may be particularly susceptible to food-related cues, with recent research indicating that overweight females tend to have an attentional bias for food-related cues, especially when hungry (Nijs et al. 2010). These recent findings extend the classic research of Schachter and colleagues, which suggested that overweight/obese individuals are more responsive to external, food-related cues than are normal-weight individuals. According to this "externality" hypothesis, obese individuals eat more than do normal-weight individuals after exposure to prominent food-related cues (e.g., Schachter 1971)

Overweight individuals appear to be susceptible to foodrelated cues, both after smelling tasty foods (Tetley et al. 2009) as well as after consuming palatable foods (McCann et al. 1992). A similar pattern appears in overweight children (Jansen et al. 2003). Researchers have suggested that the heightened reactivity to food-related cues in overweight individuals may be a factor involved in the development/ maintenance of overeating and weight gain (Tetley et al. 2009). While exposure to several types of food-cues (i.e., taste, sight, and smell) has been investigated in overweight individuals, little research has investigated the effects of food-related thoughts on cognitions and behavior. Such food-related thoughts may also be implicated in episodes of overeating and weight gain. For example, Fedoroff et al. (1997) reported that cognitive food cues (i.e., thoughts about pizza) increased participants' pizza intake. Moreover, food-related thoughts may also be implicated in overeating/overweight as a result of distorted beliefs about food.

Overweight individuals appear to have an increased susceptibly to distortions in their food-related thoughts. More specifically, they report having more extreme, selfdefeating food- and weight-related cognitions than do normal-weight individuals, including both cognitive distortions (e.g., "I ate more than I should have; now my whole diet is ruined") and learned helplessness (e.g., "I have absolutely no self-control when it comes to food"; O'Connor and Dowrick 1987). The researchers postulate that cycles of failed attempts at weight loss may lead overweight individuals to lose self-efficacy, and develop dysfunctional cognitions (including attributions about the hopelessness of losing weight), which subsequently make normalized eating and weight loss even more difficult. They suggest that focusing on modifying dysfunctional cognitions in a cognitive-behavioral treatment approach could ultimately improve weight-loss success. Supporting this postulation, recent research has demonstrated that cognitive-based treatment for obesity (including a module on dysfunctional thinking) was more efficacious for weight-loss than a behavioral-based treatment (psychoeducation, stress management, and exercise; Stahre et al. 2007). Similarly, cognitive therapy has been demonstrated to be superior than a diet- and exercise-based weight-loss treatment in preventing relapse (Werrij et al. 2009).

Just as previous research has shown effects on environmental food cues (e.g., sight and smell of food) on behavior, food-related thoughts have also been shown to affect cognitions and behavior in healthy young women, as well as women with eating disorders (Coelho et al. 2008). After imagining eating a high-caloric food, individuals reported higher negative affect than did those who imagined a neutral situation. Furthermore, individuals reported experiencing guiltier, fatter, and had a higher sense of moral wrong-doing after imagining eating a high-caloric food (compared to controls). Participants also reported a belief that they may have gained weight after just imagining eating. This phenomenon, in which imagining eating fattening foods leads individuals to feel fatter, and believe that they have gained weight and done something morally wrong, has been labeled as "thought-shape fusion" (TSF; Shafran et al. 1999). This distortion is associated with eating disorder psychopathology (Shafran and Robinson 2004), is present in individuals with anorexia nervosa (Radomsky et al. 2002), and is experienced to a greater degree in individuals with eating disorders (including bulimia nervosa and Eating Disorders Not Otherwise Specified) than in a non-eating-disordered sample (Coelho et al. 2008a). However, this distortion has also been induced in healthy young women by asking them to imagine eating fattening or high-caloric food (Coelho et al. 2010).

While TSF has not yet been studied in an overweight population, there is reason to believe that this distortion may be particularly relevant to overweight individuals, both in terms of cognitions and behavior. Individuals in a weight loss program report feeling that breaking their diet while in a weight-loss group is morally sanctionable (Mycroft 2008). While this study did not specifically focus on food-related thoughts (but rather behavior), it is entirely likely that food-related thoughts also are classified as morally acceptable or unacceptable depending on their content. If indeed this is the case, it would be expected that for (overweight) individuals who are interested in losing weight, thoughts about consuming fattening or high-caloric foods could induce TSF (including the belief that they had done something morally wrong by imagining eating this food). The experience of TSF may also have effects on eating behavior. Shafran et al. (1999) suggest that this distortion may induce either restriction (e.g., in individuals with restrictive anorexia) or episodes of overeating (e.g., in individuals with binge-eating tendencies). Overweight 
individuals exhibit counterregulatory eating, in that they eat more after consumption of a high-caloric food (compared to those who do not consume a preload; McCann et al. 1992). However, this counterregulation effect has also been shown in overweight individuals after mere exposure to the sight and smell of high-caloric foods (Jansen et al. 2003). We therefore expect that food-related thoughts can trigger similar effects in overweight individuals, perhaps as a result of experiencing the TSF distortion.

The current study was designed to investigate TSF in overweight and normal-weight females. Females were selectively recruited as they are more concerned about their weight and body image than are males, and are more interested in weight loss (Neighbors and Sobal 2007). Given previous research indicating that overweight individuals have more dysfunctional cognitions about food and weight (O'Connor and Dowrick 1987), and are more susceptible to food-related cues than are normal-weight individuals (e.g., Tetley et al. 2009) it was expected that overweight individuals would be more susceptible to a TSF induction, and would exhibit higher TSF than would normal-weight females. We also set out to study possible eating-related intentions after TSF induction. Given the possibility that both dysfunctional cognitions and exposure to food-related cues can make normalized eating more difficult, it was expected that overweight individuals would assign a lower value to dieting behavior after a TSF induction (relative to a control induction).

\section{Method}

\section{Participants}

A total of 60 females who had at least a minimally normal body weight (body mass index $(\mathrm{BMI})>18.5$ ) participated in this study in exchange for their choice of either partial course credit (for psychology students) or a voucher for $€ 7.50$. Individuals were recruited through advertisements posted around the university, as well as through advertisements on the local research recruitment website. Individuals who responded included current students, alumni, university staff, and individuals who worked in the neighborhood surrounding the university. Participants were classified as either normal-weight (BMI between 18.5 and 24.9, $M=21.5$, $S D=1.6, n=32)$ or overweight (BMI $\geq 25.0, M=27.4$, $S D=2.2, n=28$ ) based on their height and weight (in light clothing, without shoes), which was measured by the experimenter during the experimental session. All overweight participants, and $94 \%$ of normal-weight participants $(n=30)$ reported having weight-related concerns (i.e., current dieting or having the goal to try to lose or maintain their weight over the next month).
Measures

Positive and Negative Affect Schedule (PANAS; Watson et al. 1988)

The PANAS is a 20-item questionnaire which has been demonstrated to be a valid and reliable tool to assess both positive and negative affect. Participants were instructed to rate their mood "right now, at this moment" when completing the questionnaire. The obtained Cronbach's alpha for the positive affect subscale was .84 , and for the negative affect subscale was .80. This measure was translated into Dutch and subsequently back-translated into English to ensure accuracy of the translation.

\section{Restraint Scale (Polivy et al. 1988)}

The Restraint Scale is a 10-item measure used to assess concern with dieting and weight fluctuations. Items are rated on 4- or 5-point scales, and are summed to create a total score. Higher scores are indicative of higher concern with dieting/weight. The obtained Cronbach's alpa for this measure was .70. Participants were provided with the Dutch translation of this measure (Jansen et al.1988).

\section{Thought-Shape Fusion Scale, State (State TSF Scale, Coelho et al. 2010)}

Participants were asked to consider their thoughts and feelings in response to the induction that they received (i.e., imagining the situation and writing the sentence; see Procedure), and to rate the following seven items: anxiety, guilt, likelihood of weight gain, extent to which they feel fatter, how much they desired to eat a high-caloric food, the extent to which imagining the situation and/or writing the sentence was morally wrong, and the extent to which they wanted to reduce the effects of imagining the situation/ writing the sentence. Participants rated these items on a scale of $0-100$ (with 0 being 'not at all', and 100 being 'completely'), and their answers were summed to create a total score, and divided by 7 to create an average. The obtained Cronbach's alpha for this measure was .71. Participants also provided an estimation of their current weight on this questionnaire.

\section{Thought-Shape Fusion Scale, Trait (Trait TSF scale;} Shafran et al. 1999)

The TSF scale is a 34-item questionnaire which can be used to assess the general tendency to experience thoughtshape fusion. A total score can be calculated from the two subsections in this scale-the first 17 items provide a measure of TSF concept-related domains in TSF (i.e., 
likelihood, moral and feeling aspects), while the last 17 items provide a measure of TSF interpretation-related questions (i.e., participants' interpretations of what it means to think about eating fattening foods). The obtained Cronhbach's alpha for this measure was .93. This questionnaire was translated into Dutch, and back-translated into English to ensure accuracy of the translated version.

\section{Value of Dieting (Coelho et al. 2008b)}

A 6-item measure to assess participants' self-reported value of dieting was provided. Participants rated the extent to which they found the following items important: losing weight, dieting, devoting efforts to eating less, maintaining a diet while others around them are eating unhealthy foods, being thin, and overcoming urges to eat unhealthy foods. Participants rated each item on an 11-point Likert scale, and ratings were summed to create a total score, with higher scores indicated a higher value assigned to dieting (possible range: 6-66). The obtained Cronbach's alpha for this measure was .87 .

\section{Procedure}

Participants were recruited for a study which was purportedly pilot testing new measures in personality research. This cover story was used in order to prevent demand characteristics that may have arisen if participants were aware of the full purpose of the study. Scheduling of the experimental session took place via e-mail. During scheduling, participants were requested to provide some demographic information, including their height and weight (embedded among other, irrelevant questions about their native language, and their employment or program of study), to obtain a self-reported weight prior to the experimental manipulations while avoiding to prime participants with weight-related concerns at the beginning of the experimental session. Upon arrival for the session, participants signed an informed consent and were then provided with the PANAS and rated their current mood. The experimenter then asked participants to imagine one of two situations, depending on which condition to which they had been randomly assigned. The description of the conditions is below.

\section{Thought-Shape Fusion Induction}

Following the procedure employed in previous inductions of TSF (e.g., Coelho et al. 2008a; Radomsky et al. 2002; Shafran et al. 1999), participants were asked to think about food(s) that they considered to be particularly fattening or high in calories, and to imagine in vivid detail that they were eating large quantities of this food. During this imagination procedure, participants were prompted by the experimenter to imagine the sensory qualities of this act (i.e., the appearance, smell, and taste of the food). Participants were then asked to write down the sentence "I am eating ___ (inserting the name of the food(s) they were imagining).

\section{Control Induction}

Following the control induction used by Coelho et al. (2008a), participants were asked to think about a book that they had read or a movie that they had seen recently, and were asked to imagine in vivid detail chatting about this book or movie with a friend or acquaintance. Participants were then asked to write down the sentence "I am chatting about __ (inserting the name of the book or movie that they were imagining chatting about).

The induction script was read by the experimenter to each participant, and lasted approximately $30 \mathrm{~s}$, prior to asking the participants to write down the appropriate sentence. Upon completing the induction, participants were asked to complete the State TSF questionnaire, and were asked to estimate their current weight. Subsequently, participants were provided with the PANAS again, and were asked to rate their current mood. Participants were then given an opportunity to try to neutralize or negate the effects of the sentence that they had written, and were prompted by the experimenter that if they felt inclined, they could cross out the sentence, or write down another sentence (as examples as neutralizing behavior). The experimenter took note of whether participants chose to neutralize. Finally, participants were provided with the Restraint Scale, Value of Dieting questionnaire, and the Trait TSF Scale. Participants were also asked to report whether they were currently dieting to lose weight, and whether they had any weight-related goals for the next month [four response options were given: lose weight, maintain weight, gain weight, or no weight-related goals, following the approach taken by Bagozzi and Edwards (2000)]. Upon completion of the questionnaires, participants' height and weight were taken. All procedures were approved by the departmental ethical committee of the Department of Psychology and Neuroscience at Maastricht University.

\section{Results}

Participant Characteristics

Participants were between 18 and 41 years of age $(M=21.8, S D=4.3)$. The mean age of overweight participants was somewhat older $(M=22.6, S D=5.8)$ than 
that of normal-weight participants $(M=21.0, S D=2.3)$, and Levene's test of homogeneity of variance demonstrated that there was unequal variance across the groups, $F_{1,58}=4.82, P=.032$. However, an ANOVA performed on a log transform of age (to correct for the unequal variance across groups) demonstrated that this difference in age across overweight and normal-weight groups did not reach statistical significance, $F_{1,58}=2.77, P=.102$, partial $\eta^{2}=.046$.

Overweight participants reported higher levels of dietary restraint $(M=15.57, \mathrm{SD}=2.97)$ than did normal-weight participants $(M=12.28, \quad \mathrm{SD}=4.05), \quad F_{1,58}=12.55$, $P<.001$, partial $\eta^{2}=.178$. Moreover, dietary restraint and BMI were highly correlated $(r=.525, P<.001)$, suggesting that overweight status should be adjusted for potential confounders such as dietary restraint (see e.g., Provencher et al. 2005) ${ }^{1}$. Therefore, dietary restraint was entered as a covariate for all analyses which included weight status as an independent variable, as in previous research comparing overweight with normal-weight individuals (e.g., Temple et al. 2008).

\section{Manipulation Check}

In order to ensure that the control induction was an appropriate neutral control and did not influence affect, participants' responses on the positive and negative subscales of the PANAS were analyzed using a repeatedmeasures ANOVA with induction condition entered as the independent variable, and pre- and post-induction scores on the positive and negative affect subscales entered as within-subjects variables. There was a significant interaction between time and induction condition on positive affect, $F_{1,56}=10.69, P \leq .001$, partial $\eta^{2}=.160 . T$ tests indicated that participants in the TSF condition reported significantly less positive affect post-induction $(M=26.4$, $S D=6.1)$ compared to pre-induction $(M=29.5$, $\left.S D=5.05, t_{30}=6.19, P \leq .001\right)$. In contrast, for individuals who received the control induction, there were no significant differences in positive affect pre-induction $(M=28.5, S D=6.5)$ versus post-induction $(M=28.1$, $S D=6.7), t_{28}=.65, P=.520$. There were no significant

\footnotetext{
${ }^{1}$ Dietary restraint and BMI are interrelated factors, with many studies reporting that individuals with high dietary restraint have higher BMI than do those low in dietary restraint (see e.g., Trottier et al. 2005). Dietary restraint, which assesses both concern with dieting and weight fluctuations, could in part account for failures in maintaining normalized eating, and subsequent differences between overweight and normal-weight individuals. However, there are further differences between overweight and normal-weight individuals that can potentially account for differences in eating behavior, which include motivation to eat (Temple et al. 2008), attention to food (Nijs et al. 2010) and social adversity (Salvy et al. 2011).
}

effects of induction condition on negative affect across time, $F_{1,56}=.159, P>.05$, partial $\eta^{2}=.003$.

\section{Trait TSF}

An ANCOVA was conducted on trait TSF scores, with dietary restraint entered as a covariate. Total trait TSF scores were subjected to a square root transform to address violations of homogeneity of variance and normality. Dietary restraint had a significant effect on trait TSF scores, $F_{1,54}=40.54, P \leq .001$, partial $\eta^{2}=.429$. A significant main effect of condition emerged $\left[F_{1,54}=8.20\right.$, $P \leq .01$, partial $\eta^{2}=.132$ ], with individuals in the TSF induction condition reporting significantly higher trait TSF scores than those in the control condition. There were no main effects of weight status on trait TSF scores, $F_{1,54}=.14, P>.05$, partial $\eta^{2}=.003$; however, there was a significant interaction between condition and weight status, $F_{1,54}=5.82, P \leq .05$, partial $\eta^{2}=.097$. NeumanKeuls post-hoc analyses demonstrated that the normalweight group exposed to the control induction had lower trait TSF scores than did all other groups $(P<.01$; see Fig. 1).

\section{State TSF}

An ANCOVA was conducted in order to assess the 'state' experience of TSF, with dietary restraint entered as a covariate. To correct for violations of the assumptions of the ANOVA (homogeneity of variance and normality), the data were subjected to a square root transformation. There was a trend towards a significant effect of dietary restraint on state TSF scores, $F_{1,55}=3.65, P \leq .065$, partial $\eta^{2}=.062$. There was a significant main effect of induction condition $\left[F_{(1,55)}=14.57, P \leq .001\right.$, partial $\left.\eta^{2}=.209\right]$, with participants in the TSF induction condition reporting

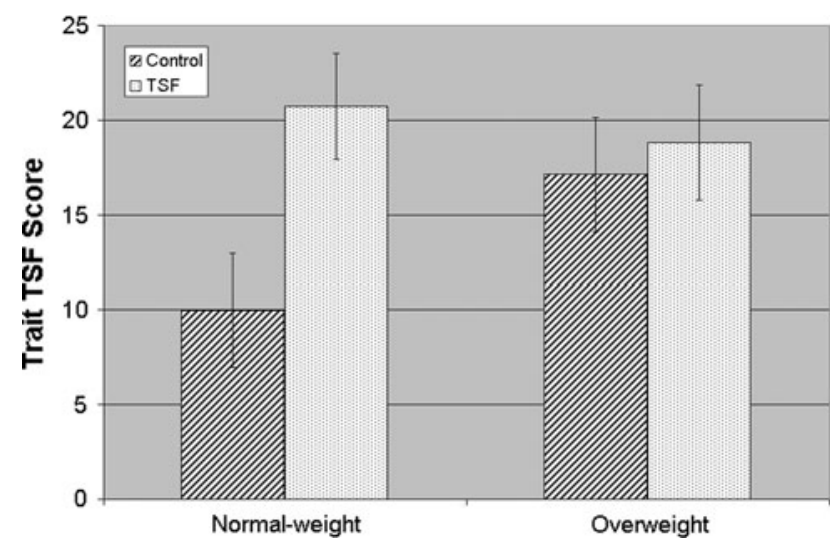

Fig. 1 Mean trait TSF scores (with standard error) in normal-weight $(n=32)$ and overweight $(n=28)$ participants across the experimental conditions 
Table 1 Mean values (with standard deviation) on state TSF and value of dieting across groups: normal-weight individuals who received the control induction $(n=15)$ or TSF induction $(n=17)$, and overweight individuals who received the control induction $(n=14)$ or TSF induction $(n=14)$

\begin{tabular}{lllll}
\hline & \multicolumn{2}{l}{ Normal-Weight } & & \multicolumn{2}{l}{ Overweight } \\
\cline { 2 - 3 } & Control induction & TSF induction & & Control induction \\
\hline State TSF average & $7.5(8.3)^{\mathrm{a}}$ & $25.1(17.0)^{\mathrm{b}}$ & $8.2(6.0)^{\mathrm{a}}$ & TSF induction \\
Value of dieting & $27.3(11.4)^{\mathrm{a}}$ & $33.9(10.2)^{\mathrm{b}}$ & $39.4(8.7)^{\mathrm{b}}$ & $13.6(11.2)^{\mathrm{a}}$ \\
\hline
\end{tabular}

Means for a variable that differ significantly from one another are indicated by different superscripts

higher state TSF than those who received a control induction. A significant main effect of weight status also emerged $\left[F_{(1,55)}=4.13, P \leq .05\right.$, partial $\left.\eta^{2}=.070\right]$, in which normal-weight participants reported higher levels of state TSF than did overweight participants. These main effects were qualified by a significant interaction between the independent variables $\left[F_{(1,55)}=4.19, P \leq .05\right.$, partial $\left.\eta^{2}=.071\right]$. Neuman-Keuls post-hoc tests indicated that normal-weight individuals in the TSF induction condition reported higher state TSF than did all other groups $(P<.05$; see Table 1$)$. No other significant differences between groups emerged.

As another indication of whether participants were experiencing state TSF, and overestimating their current weight after TSF induction, the difference was calculated between participants' self-reported weight on the state TSF questionnaire and their self-reported weight which was obtained at the time of scheduling the experiment. An ANCOVA was subsequently conducted on this difference score (controlling for dietary restraint). There were no main effects of either induction condition $\left[F_{(1,52)}=.68, P>.05\right.$, partial $\left.\eta^{2}=.013\right]$ or weight status $\left[F_{(1,52)}=2.27, P>.05\right.$, partial $\left.\eta^{2}=.042\right]$ on the difference score, nor was there a significant interaction $\left(F_{(1,52)}=.79, \quad P>.05\right.$, partial $\left.\eta^{2}=.015\right)$. On average, regardless of experimental condition, participants reported a slightly higher weight during the experimental session than that which they reported prior to the experiment $\left(M_{\text {difference }}=.75 \mathrm{~kg}, S D=1.4\right)$.

\section{Value of Dieting}

An ANCOVA was conducted on value of dieting scores, with weight status and condition entered as independent variables, and dietary restraint entered as a covariate. There was a significant effect of dietary restraint on value of dieting, $F_{1,55}=29.35, P \leq .001$, partial $\eta^{2}=.348$. There were no significant main effects of either condition $\left[F_{(1,55)}=1.69, P>.05\right.$, partial $\left.\eta^{2}=.030\right]$ or weight status $\left[F_{(1,55)}=.70, P>.05\right.$, partial $\left.\eta^{2}=.013\right]$ on self-reported value of dieting. However, there was a significant interaction between these two variables, $F_{(1,55)}=4.78$, $P \leq .05$, partial $\eta^{2}=.080$. Neuman-Keuls post-hoc analyses demonstrated that the normal-weight individuals who received the control induction reported valuing dieting significantly less than did individuals in all other groups $(P<.05$; see Table 1$)$.

\section{Neutralization}

There were no statistically significant differences in neutralization behavior between the TSF induction $(6.5 \%$ neutralized) and the control induction ( $0 \%$ neutralized; $P=.263$, Fisher's Exact Test).

\section{Discussion}

The lack of response of overweight women exposed to a TSF induction (relative to a control induction) went against the initial hypothesis that overweight individuals would be more susceptible to TSF. There was some partial support for the fact that overweight individuals in a neutral state are more susceptible to TSF than are normal-weight individuals, as they reported higher trait TSF scores (regardless of their experimental condition) than did normal-weight individuals in the control condition. However, this difference did not emerge for the state TSF scores. Ceiling effects are unlikely to account for this lack of response, given that the mean TSF scores of overweight individuals were well below the possible maximum of 100 . The initial hypothesis that overweight individuals would be more susceptible to TSF inductions than would normal-weight individuals was partially based on the findings of O'Connor and Dowrick (1987), who reported more food- and weightrelated distortions in overweight individuals compared to normal-weight individuals. However, the current study was focused on investigating one specific type of food-/weightrelated distortion (namely, TSF), as opposed to the range of cognitions and distortions assessed by O'Connor and Dowrick.

In fact, the results demonstrated normal-weight women were more susceptible to a TSF induction than were overweight women. This was demonstrated in both the state and trait TSF scores, with normal-weight (but not 
overweight) women reporting increased TSF after a TSF induction, compared to a control induction. Furthermore, exposure to a TSF induction also increased the value normal-weight women assigned to dieting, suggesting that thoughts of eating high-caloric foods may trigger dieting or other changes in eating behaviors in this group. This general pattern of results, in which normal-weight (but not overweight) individuals with weight concerns are more dissatisfied with their weight after exposure to food-related cues is consistent with some previous research (Fett et al. 2009). More specifically, Fett and colleagues demonstrated that looking at foods (without eating them), and focusing on the thoughts and feelings generated when seeing the food, decreased body satisfaction in lean (but not overweight) restrained eaters. The current study therefore extends their findings by demonstrating that mere thoughts about eating fattening food (in the absence of actually seeing this food) can induce TSF (which includes a feeling of fatness) in lean but not overweight females.

Fett et al. (2009) are not alone in their discovery that normal-weight individuals exhibit increased susceptibility to food-cue exposure relative to overweight individuals. Normal-weight individuals also have differential "wanting" of food after exposure to food-related cues compared to overweight individuals. Normal-weight individuals (i.e., those who maintain their weight below a BMI of 25) reported decreased wanting for high-caloric food after exposure to tempting food words, whereas overweight individuals reported increased wanting (Ouwehand and Papies 2010). The authors suggest that this differential wanting may account for (lack of) success in weight maintenance, as overweight individuals appear to deactivate their dieting-related goals upon exposure to foodrelated cues, whereas temptations trigger self-regulation in normal-weight individuals. The current study provides partial support for this postulation, given that normalweight individuals reported a higher value of dieting after the TSF induction than the control induction (although there was not a decrease in the value of dieting of overweight individuals). Putting together the current pattern of findings with those of Ouwehand and Papies 2010, and Fett et al. (2009), a pattern emerges in which normal-weight individuals respond to food-related cues with cognitions associated with eating less (i.e., increased feelings of fatness, body dissatisfaction, and decreased food wanting). In contrast, overweight individuals appear to respond to foodrelated cues with increased wanting for the food, in the absence of cognitions that may motivate reduced food consumption of high-caloric foods(such as body dissatisfaction). Overweight individuals therefore appear to be set up for continued failure to self-regulate, given the toxic food environment in which they are constantly confronted with food-related cues.
Further contributing to differences between normalweight and overweight individuals in the current study is the possibility that weight gain and obesity may be particularly threatening to normal-weight individuals. Research has demonstrated that lean individuals are more likely than are overweight individuals to make considerable hypothetical sacrifices (e.g., being divorced, severely depressed, alcoholic, or living a shorter life) rather than be obese (Schwartz et al. 2006). Similarly, normal-weight (but not overweight) individuals are more likely to overestimate their deviation above their ideal weight (Klesges 1983). Therefore, perhaps the TSF induction was more threatening to normal-weight females, and amplified their (mis)estimation of their body weight.

It is important to note that weight-related concerns were predominant in our sample, with only 2 normal-weight individuals ( $6 \%$ of the normal-weight sample) reporting no weight-related goals/dieting behavior. Dietary restraint was controlled for in the statistical analyses; however, in future research aimed at determining the factors which increase susceptibility to cognitive distortions such as TSF, it may be important to consider the role of weight-related concerns. For example, we did not directly measure participants' body image or weight-related perceptions. Young women who are within a normal-weight range often perceive themselves to be overweight, with some research indicating that nearly $85 \%$ of adolescent girls who classified themselves as overweight had a BMI under 25 (Pritchard et al. 1997). Perhaps it is these normal-weight individuals who are weight-concerned and overestimate their degree of overweight who are particularly susceptible to TSF inductions. Similarly, perhaps overweight individuals who do not have strong weight-related concerns are less likely to experience cognitive distortions. For example, Hunt and Rosen (1981) initially predicted that obese individuals would have more maladaptive cognitions about food/weight/shape than would normal-weight individuals; however, they were unable to detect any differences between groups, and speculated that the fact that their obese participants were non-dieting may have attenuated any dysfunctional cognitions. Similarly, Jakatdar et al. (2006) report that preoccupation with weight was more associated with body-image distortions than was actual BMI.

The malleability of normal-weight individuals' responses on the trait TSF scale is a novel finding, as previous research has not demonstrated any main effects of TSF induction on trait TSF scores (Coelho et al. 2010). This finding suggests that the normal-weight individuals in the current study were particularly susceptible to the TSF induction, to the extent that they overestimated their general tendencies towards TSF after thinking about eating fattening foods (reporting higher scores on the trait TSF 
scale than did normal-weight individuals in the control induction condition). Although this finding is contrary to one previous study, few studies have been conducted investigating the effects of TSF induction, and several of the other studies did not report analyses on possible changes in trait TSF scores post-TSF induction (Shafran et al. 1999) or relative to a control induction (Coelho et al. 2008a). On the one hand, this finding brings into question whether this measure is truly a 'trait' measure, given the malleability after TSF induction in normal-weight individuals. On the other hand, exposure to certain types of inductions can alter individuals' trait evaluations of themselves. More specifically, individuals have lower selfappraisals of their personality traits (e.g., kindness, friendliness, and considerateness) after a negative mood induction compared to a positive mood induction (Brown and Mankowski 1993). Individuals with low self-esteem appeared to be particularly vulnerable to the effects of a negative mood induction, reporting lower appraisals of themselves than did those with high self-esteem.

Further work on the psychometric properties of the trait measure of TSF is in order to elucidate whether responses on this questionnaire are malleable based on the state of participants. Given the findings of Brown and Mankowski (1993), it also may be that 'trait' evaluations of TSF can be altered by individuals' mood state or exposure to TSF inductions. Future research could also address some of the limitations inherent in the current study, including the participant sample and the reliance on self-report data. We selected and classified our sample based on objective weight and height (normal-weight: $\mathrm{BMI}>18.5$ and $<25$; overweight: $\mathrm{BMI} \geq 25$ ), but did not select for further characteristics (e.g., current dieting attempts, body dissastisfaction, or past weight history). We controlled for current dietary restraint in our analyses, in an attempt to tease apart body weight from chronic dieting tendencies, as research has shown that chronic dieting, as opposed to body weight per se, may account for many behavioural differences in food intake and reactivity to food-related cues (see e.g., Herman and Mack 1975). However, to investigate the effects of body weight on TSF reactivity more precisely, it would be advisable to match groups on relevant factors. It also could provide more insight to select a pathological sample (e.g., overweight individuals who are diagnosed with binge-eating disorder), as these individuals may be more susceptible to TSF inductions and the possibility of floor effects would therefore be reduced. Finally, we used self-report questionnaires to assess the value that participants assign to dieting, to give an indication of whether TSF inductions may have effects on eating behavior; however, use of actual behavioral measures (e.g., food choice or food intake) would provide further support for the postulation that the effects of TSF induction may generalize to eating behavior, as well as affect cognitions.

In conclusion, the current study demonstrates that normal-weight, but not overweight, females are susceptible to a TSF induction and report higher state and trait TSF scores, as well as assign a higher value to dieting, after a TSF induction as compared to a control induction. There may be factors that make some individuals more susceptible to TSF inductions, such as the extent to which thoughts about eating fattening foods and becoming fat(ter) are threatening to the individual, and the extent to which these thoughts induce wanting for high-caloric foods. This research provides further support for the fact that normalweight females in the general population can be induced with TSF, and suggests the importance of further investigating the role of cognitive distortions (such as TSF) on eating-related behavior and body image.

Acknowledgments This research was supported by a Marie Curie Intra European Fellowship within the 7th European Community Framework Program awarded to the first author. We would like to thank Anne Roefs and Chantal Nederkoorn for their technical assistance with this research. Portions of this research were presented at the World Congress of Behavioral and Cognitive Therapies, Boston, June 2010.

\section{References}

Bagozzi, R. P., \& Edwards, E. A. (2000). Goal-striving and the implementation of goal intentions in the regulation of body weight. Psychology and Health, 15, 255-270.

Brown, J. D., \& Mankowski, T. A. (1993). Self-esteem, mood, and self-evaluation: Changes in mood and the way you see you. Journal of Personality and Social Psychology, 64, 421-430.

Brownell, K. D. (2002). The environment and obesity. In C. G. Fairburn \& K. D. Brownell (Eds.), Eating disorders and obesity: A comprehensive handbook (2nd ed., pp. 433-438). New York: Guildford Press.

Coelho, J. S., Carter, J. C., McFarlane, T., \& Polivy, J. (2008a). "Just looking at food makes me gain weight": Experimental induction of thought-shape fusion in eating- disordered and non-eatingdisordered women. Behaviour Research and Therapy, 46, 219-228.

Coelho, J. S., Polivy, J., Herman, C. P., \& Pliner, P. (2008b). Effects of food-cue exposure on dieting-related goals: A limitation to counteractive-control theory. Appetite, 51, 347-349.

Coelho, J. S., Roefs, A., \& Jansen, A. (2010). The role of food-cue exposure and negative affect in the experience of thought-shape fusion. Journal of Behavior Therapy and Experimental Psychiatry, 41, 409-417.

Fedoroff, I. C., Polivy, J., \& Herman, C. P. (1997). The effect of preexposure to food cues on the eating behavior of restrained and unrestrained eaters. Appetite, 28, 33-47.

Fett, A.-K., Lattimore, P., Roefs, A., Geschwind, N., \& Jansen, A. (2009). Food cue exposure and body image satisfaction: The moderating role of BMI and dietary restraint. Body Image, 6, $14-18$.

Herman, C. P., \& Mack, D. (1975). Restrained and unrestrained eaters. Journal of Personality, 43, 647-660. 
Hill, J. O., \& Peters, J. C. (1998). Environmental contributions to the obesity epidemic. Science, 280, 1371-1374.

Hunt, D. A., \& Rosen, J. C. (1981). Thoughts about food by obese and nonobese individuals. Cognitive Therapy and Research, 5, 317-322.

Jakatdar, T. A., Cash, T. F., \& Engel, E. K. (2006). Body-image thought processes: The development and initial validation of the assessment of body-image cognitive distortions. Body Image, 3, $325-333$.

James, P. T. (2004). Obesity: The worldwide epidemic. Clinics in Dermatology, 22, 276-280.

Jansen, A., Oosterlaan, J., Merckelbach, H., \& Van den Hout, M. (1988). Nonregulation of food intake in restrained, emotional and external eaters. Journal of Psychopathology and Behavioral Assessment, 10, 345-353.

Jansen, A., Theunissen, N., Schlecten, K., Nederkoorn, C., Boon, B., Mulkens, S., et al. (2003). Overweight children overeat after exposure to food cues. Eating Behaviors, 4, 197-209.

Klesges, R. C. (1983). An analysis of body image distortions in a nonpatient population. International Journal of Eating Disorders, 2, 35-41.

McCann, K. L., Perri, M. G., Nezu, A. M., \& Lowe, M. R. (1992). An investigation of counterregulatory eating in obese clinic attenders. International Journal of Eating Disorders, 12, 161-169.

Mycroft, H. (2008). Morality and accountability in a commercial weight management group. Journal of Health Psychology, 13, $1040-1050$.

National Institutes of Health (2009). We can! parent tips: Healthy families, healthy weight. Downloaded from the National Heart, Lung, and Blood Institute (April 14, 2009).Url:www.nhlbi.nih.gov/ health/public/heart/obesity/wecan/downloads/physician2.pdf.

Neighbors, L. A., \& Sobal, J. (2007). Prevalence and magnitude of body weight and shape dissatisfaction among university students. Eating Behaviors, 8, 429-439.

Nijs, I. M. T., Muris, P., Euser, A. S., \& Franken, I. H. A. (2010). Differences in attention to food and food intake between overweight/obese and normal-weight females under conditions of hunger and satiety. Appetite, 54, 243-254.

O'Connor, J. O., \& Dowrick, P. W. (1987). Cognitions in normal weight, overweight, and previously overweight adults. Cognitive Therapy and Research, 11, 315-326.

Ouwehand, C., \& Papies, E. K. (2010). Eat it or beat it. The differential effects of food temptations on overweight and normal-weight restrained eaters. Appetite, 55, 56-60.

Polivy, J., Herman, C. P., \& Howard, K. (1988). The restraint scale: Assessment of dieting. In M. Hersen \& A. S. Bellack (Eds.), Dictionary of behavioral assessment techniques (pp. 377-380). New York: Pergamon Press.

Pritchard, M. E., King, S. L., \& Czajka-Nairns, D. M. (1997). Adolescent body mass indices and self-perception. Adolescence, $32,863-880$
Provencher, V., Pérusse, L., Bouchard, L., Drapeau, V., Bouchard, C., Rice, T., et al. (2005). Familial resemblance in eating behaviors in men and women from the quebec family study. Obesity Research, 13, 1624-1629.

Radomsky, A. S., de Silva, P., Todd, G., Treasure, J., \& Murphy, T. (2002). Thought-shape fusion in anorexia nervosa: An experimental investigation. Behaviour Research and Therapy, 40, 1169-1177.

Salvy, S., Bowker, J. C., Nitecki, L. A., Kluczynski, M. A., Germeroth, L. J., \& Roemmich, J. N. (2011). Impacted of simulated ostracism on overweight and normal-weight youths' motivation to eat and food intake. Appetite, 56, 39-45.

Schachter, S. (1971). Some extraordinary facts about obese humans and rats. American Psychologist, 26, 129-144.

Schwartz, M. B., Vartanian, L. R., Nosek, B. A., \& Brownell, K. D. (2006). The influence of one's own body weight on implicit and explicit anti-fat bias. Obesity, 14, 440-447.

Shafran, R., \& Robinson, P. (2004). Thought-shape fusion in eating disorders. British Journal of Clinical Psychology, 43, 399-407.

Shafran, R., Teachman, B. A., Kerry, S., \& Rachman, S. (1999). A cognitive distortion associated with eating disorders: Thoughtshape fusion. British Journal of Clinical Psychology, 38, 167-179.

Stahre, L., Tärnell, B., Håkanson, C.-E., \& Hällström, T. (2007). A randomized controlled trial of two weight-reducing short-term group treatment programs for obesity with an 18-month followup. International Journal of Behavioral Medicine, 14, 48-55.

Temple, J. L., Legierski, C. M., Giacomelli, A. M., Salvy, S.-J., \& Epstein, L. H. (2008). Overweight children find food more reinforcing and consume more energy than do nonoverweight children. American Journal of Clinical Nutrition, 87, $1121-1127$.

Tetley, A., Brunstrom, J., \& Griffiths, P. (2009). Individual differences in food-cue reactivity: The role of BMI and everyday portion size. Appetite, 52, 614-620.

Trottier, K., Polivy, J., \& Herman, C. P. (2005). Effects of exposure to unrealistic promises about dieting: Are unrealistic promises about dieting inspirational? International Journal of Eating Disorders, 37, 142-149.

Watson, D., Clark, L. A., \& Tellegen, A. (1988). Development and validation of brief measures of positive and negative affect: The PANAS scales. Journal of Personality and Social Psychology, 54(6), 1063-1070.

Werrij, M. Q., Jansen, A., Mulkens, S., Elgersma, H. J., Ament, A. J. H. A., \& Hospers, H. (2009). Adding cognitive therapy to dietetic treatment is associated with less relapse in obesity. Journal of Psychosomatic Research, 67, 315-324.

Wing, R. R., \& Phelan, S. (2005). Long-term weight loss maintenance. American Journal of Clinical Nutrition, 82, 222-225. 